\title{
Medium-Term Effects of Insulin Degludec on Patients with Type 1 Diabetes Mellitus
}

\author{
Rie Nakae $\cdot$ Yoshiki Kusunoki $\cdot$ Tomoyuki Katsuno $\cdot$ Masaru Tokuda $\cdot$ \\ Takafumi Akagami · Kazuki Murai · Tomoya Hamaguchi · Jun-ichiro Miyagawa • \\ Mitsuyoshi Namba
}

Published online: 17 May 2014

(C) The Author(s) 2014. This article is published with open access at Springerlink.com

\begin{abstract}
Objective The aim of this study was to analyze the changes in daily blood glucose fluctuation and insulin dose in patients with type 1 diabetes mellitus (T1DM) undergoing basal-bolus therapy following a switching of basal insulin used from insulin glargine or detemir to insulin degludec.

Methods Seven patients with T1DM were enrolled. All patients treated with insulin glargine or detemir twice daily were switched to insulin degludec with 80-90\% of the prior insulin dose. During the study period, the basal insulin doses were adjusted by the attending physician. The patients underwent continuous glucose monitoring before, 3 days after, and 24 weeks after switching to insulin degludec. The daily insulin dose was analyzed before, 3 days after, and 24 weeks after switching. Glycated hemoglobin levels were measured before and 24 weeks after switching. Results The blood glucose profile did not change significantly before and after switching. On the other hand, the total daily insulin dose and total daily basal insulin dose decreased significantly 24 weeks after switching.

Discussion In patients with T1DM undergoing insulin glargine or detemir treatment, it is possible to achieve similar glycemic control in the medium term with a once daily, lower dose of insulin degludec.
\end{abstract}

R. Nakae · Y. Kusunoki $(\bowtie) \cdot$ M. Tokuda · T. Akagami · K. Murai · T. Hamaguchi - J. Miyagawa - M. Namba Division of Diabetes, Endocrinology, and Metabolism, Department of Internal Medicine, Hyogo College of Medicine, 1-1 Mukogawa-cho, Nishinomiya, Hyogo 663-8501, Japan e-mail: ykusu@hyo-med.ac.jp

\section{T. Katsuno}

Division of Innovative Diabetes Treatment, Hyogo College of Medicine, Nishinomiya, Japan

\section{Introduction}

Patients with type 1 diabetes mellitus (T1DM) often require multiple daily injection (MDI) therapy consisting of a basal dose of intermediate- or long-acting insulin coupled with a rapid- or ultra-rapid-acting insulin as a supplemental agent [1]. For patients with T1DM suffering from the lack of endogenous insulin secretion, stable supplementation of basal insulin is essential to achieve good glycemic control [1]. Several reports have shown that to achieve glycemic control in patients with T1DM, it is necessary to inject basal insulin in two divided doses twice a day [2, 3].

Recently, insulin degludec (Novo Nordisk A/S, Bagsværd, Denmark), a soluble dihexamer preparation that forms stable and soluble multihexamers after subcutaneous injection, has been developed [4]. The multihexamers remain at the injection site for some time and gradually dissolve to release insulin monomers into the blood in a slow and sustained manner [4]. Degludec has prolonged activity as it binds to albumin via fatty acid side chains both at the subcutaneous injection site and in the blood [4]. In 22 Japanese patients with T1DM who received subcutaneous administration of insulin degludec at 0.4 units (U)/ $\mathrm{kg}$ once daily for 6 days, the duration of action was reported to be over $26 \mathrm{~h}$ [5].

In our previous study, we showed that it was possible to achieve similar glycemic control by once-daily injection of a lower dose of insulin degludec in patients with T1DM who had been treated with insulin glargine or detemir twice daily [6]. Another study reported that insulin degludec lessens day-to-day variability of blood glucose levels as compared with insulin glargine [7]. However, there is no report on the medium-term effects of insulin degludec on glucose fluctuation and nocturnal hypoglycemia in patients with T1DM. 
This is a follow-up of our previous study on insulin degludec [6]. The aim of this study was to analyze the mediumterm effects of switching from insulin glargine or detemir to insulin degludec on daily blood glucose fluctuation, glycated hemoglobin $\left(\mathrm{HbA}_{1 \mathrm{c}}\right)$, and total daily insulin dose (TDD).

\section{Methods}

\subsection{Subjects}

In our previous study, ten patients were treated with twicedaily injection of insulin glargine or detemir. However, three patients refused to undergo continuous glucose monitoring (CGM) 24 weeks after switching for personal reasons. The subjects of this study were seven patients (three males and four females) with T1DM who had been treated with MDI therapy for over 12 months at the Division of Diabetes, Endocrinology, and Metabolism, Department of Internal Medicine, Hyogo College of Medicine (Hyogo, Japan). Inclusion criteria were treatment with insulin glargine or detemir as basal insulin therapy, $\mathrm{HbA}_{1 \mathrm{c}}$ of $\geq 6.0 \%$, ad libitum serum C-peptide immunoreactivity (CPR) of $<0.3 \mathrm{ng} / \mathrm{mL}$, and severe impairment of endogenous insulin secretion. Exclusion criteria were severe hepatic and/or renal impairment, severe infection, perioperative status, severe trauma, pregnancy or desire to become pregnant, ischemic heart disease (current or past), cancer, and other criteria by which the leading physician judges the patient as unsuitable. The study subjects underwent CGM by wearing a portable monitor. This study was approved by the Ethics Committee of Hyogo College of Medicine (No. 1425) and was registered in the University Hospitals Medical Information Network registry (No. 000010893). All procedures were in accordance with the ethical standards of the responsible committee on human experimentation (institutional and national) and with the Helsinki Declaration of 1975, as revised in 2000 and 2008. Informed consent was obtained from all patients for being included in the study.

\subsection{Medications}

Seven patients enrolled in this study were treated by twicedaily injection of insulin glargine or detemir. According to the degludec dosage guide in Japan (Novo Nordisk Pharma, Ltd., Tokyo, Japan) [5], patients were started with twice-daily injection of insulin glargine or detemir and then switched to once-daily injection of degludec at an initial dose that was 80-90\% of the respective dose of glargine or detemir [5].

Degludec was administered at a time of day suitable for their lifestyle. During the study period, the basal insulin doses were adjusted by the attending physician in a titration protocol as shown in Table 1 .
Table 1 Fasting plasma glucose levels and basal insulin doses during the 24-week study period

\begin{tabular}{ll}
\hline $\begin{array}{l}\text { Fasting plasma glucose level } \\
(\mathrm{mg} / \mathrm{dL})\end{array}$ & Dose adjustment of degludec \\
\hline$\leq 80$ & Decreased $10-20 \% /$ day \\
$81-150$ & No adjustment \\
$151-200$ & $\begin{array}{l}\text { Increased } 10 \% / \text { day (or } 1-2 \text { U/day) } \\
\text { Increased } 10-20 \% / \text { day } \\
\text { (or } 2-3 \text { U/day) }\end{array}$ \\
\hline
\end{tabular}

$U$ units

For pre-prandial insulin supplementation, insulin aspart or lispro was administered at a dose set by the carbohydrate counting method, which remained unchanged throughout the study period.

\subsection{Meals}

During the study period, all patients were given a test diet (1,500-1,600 kcal/day; 55-60\% carbohydrates, $15-20 \%$ protein, $20-25 \%$ fat) when CGM evaluation was performed before and 3 days and 24 weeks after switching to insulin degludec (Fig. 1).

\subsection{Continuous Glucose Monitoring (CGM)}

The study design is shown in Fig. 1. CGM was performed using an $\mathrm{iPro}^{\mathrm{TM}} 2$ (Medtronic Minimed, Northridge, CA, USA) monitor before, 3 days after, and about 24 weeks after switching to insulin degludec. Evaluation of the CGM data was started while the patients were using glargine or detemir and was continued until the third day after switching to insulin degludec, when its blood concentration reached steady state [5]. The CGM data obtained before switching and at the third day after switching were then compared. Furthermore, evaluation of the glucose profile at 24 weeks was conducted on the second day.

\subsection{Glycated Hemoglobin}

$\mathrm{HbA}_{1 \mathrm{c}}$ was measured just before switching and when CGM evaluation was performed at about 24 weeks after switching to insulin degludec.

\subsection{Statistical Analysis}

Variables are expressed as the mean $\pm \mathrm{SD}$. The Wilcoxon signed-ranks test was used to compare daily glucose fluctuations and the change of insulin dose before and 3 days after switching to degludec. This test was also used to compare daily glucose fluctuations and the change of 


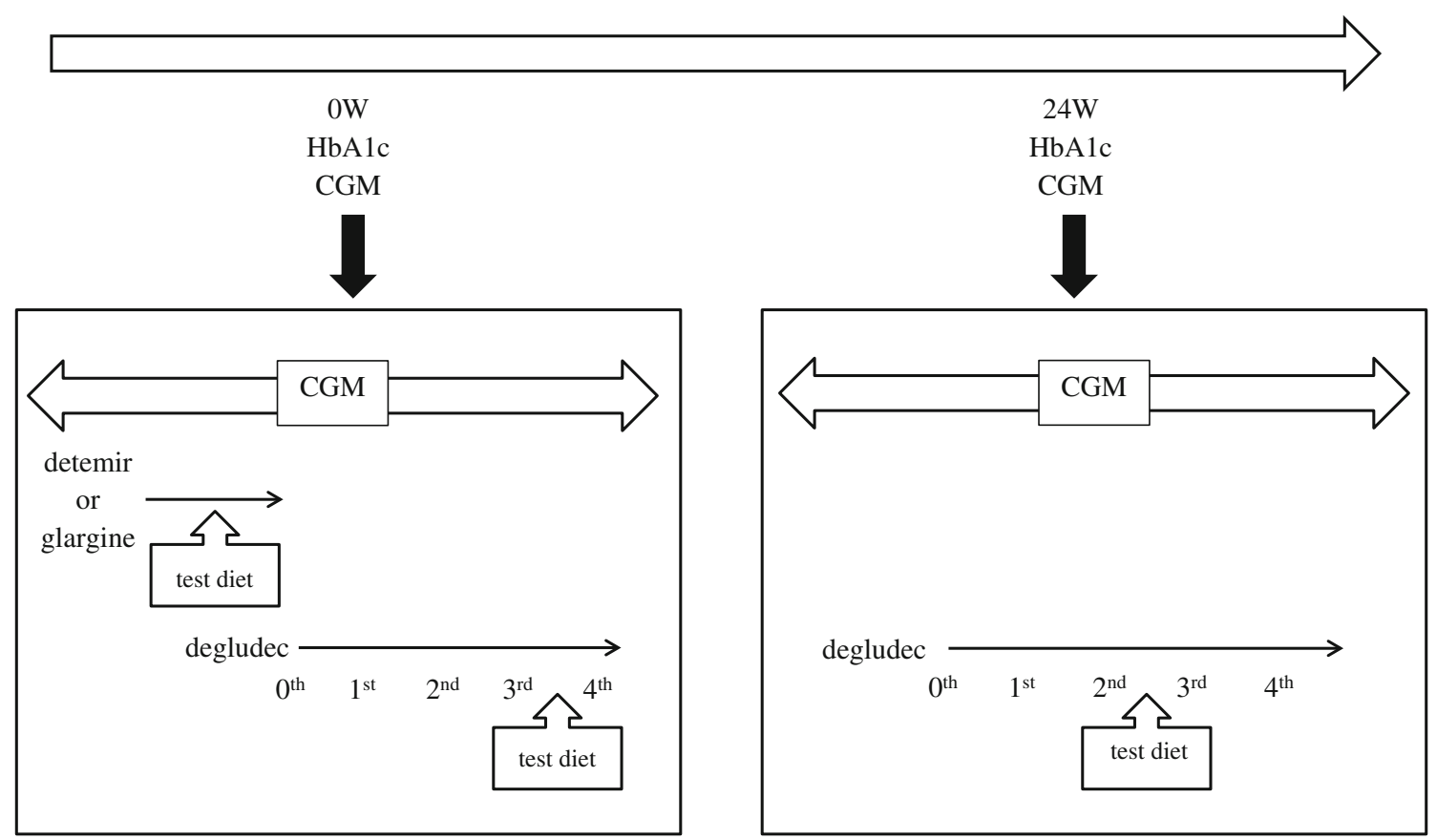

Fig. 1 Study design. $C G M$ continuous glucose monitoring, $H b A_{l c}$ glycated hemoglobin, $W$ week

$\mathrm{HbA}_{1 \mathrm{c}}$ and insulin doses until about 24 weeks after switching to degludec. StatView version 5.0 software (SAS Institute Inc., Cary, NC, USA) was used for all analyses.

\section{Results}

\subsection{Patient Characteristics}

Five of the seven patients included in this study were diagnosed as having T1DM by the detection of islet-associated autoantibodies, and the other two cases by their medical history. In all cases, ad libitum CPR levels were less than $0.03 \mathrm{ng} / \mathrm{mL}$ (not detectable).

The clinical characteristics of the patients are shown in Table 2. The mean age ( \pm standard deviation) was $51.9 \pm 16.6$ years, $\mathrm{HbA}_{1 \mathrm{c}}$ was $7.3 \pm 0.9 \%$, and the body mass index was $21.3 \pm 2.9 \mathrm{~kg} / \mathrm{m}^{2}$. TDD was $0.71 \pm$ $0.40 \mathrm{U} / \mathrm{kg}$ and total daily basal insulin dose (TBD) was $0.32 \pm 0.17 \mathrm{U} / \mathrm{kg}$. The ratio of TBD to TDD (TBD/TDD) was $44.8 \pm 12.8 \%$. Insulin glargine was used as the basal insulin preparation in six of seven patients. As supplemental insulin, ultra-rapid-acting insulin was used in all patients, insulin lispro in two patients, and insulin aspart in five.

\subsection{Insulin Dose}

Insulin degludec was administered at $80-90 \%$ of the dose of the prior insulin, resulting in a significant decrease in
Table 2 Characteristics of enrolled patients

\begin{tabular}{|c|c|}
\hline Variables & $\begin{array}{l}\text { Detemir or Glargine } \\
\text { twice daily }\end{array}$ \\
\hline$n$ & 7 \\
\hline Sex (male:female) & $3: 4$ \\
\hline Age (years) & $51.9 \pm 16.6$ \\
\hline $\mathrm{HbA}_{1 \mathrm{c}}(\%, \mathrm{NGSP})$ & $7.3 \pm 0.9$ \\
\hline BMI $\left(\mathrm{kg} / \mathrm{m}^{2}\right)$ & $21.3 \pm 2.9$ \\
\hline Duration of diabetes mellitus (years) & $13.7 \pm 6.5$ \\
\hline Glargine (number of cases) & 6 \\
\hline Detemir (number of cases) & 1 \\
\hline TDD/Wt (U/kg) & $0.71 \pm 0.40$ \\
\hline TBD/Wt (U/kg) & $0.32 \pm 0.17$ \\
\hline TBD/TDD (\%) & $44.8 \pm 12.8$ \\
\hline
\end{tabular}

Data are given as mean \pm SD unless otherwise stated

$H b A_{I c}$ glycated hemoglobin, NGSP national glycohemoglobin standardization program, $T B D$ total daily dose of basal insulin, $T D D$ total daily dose of insulin, $U$ units, $W t$ weight

TDD from $0.71 \pm 0.40$ to $0.67 \pm 0.39 \mathrm{U} / \mathrm{kg}(p=0.02)$ (Fig. 2a). TBD also showed a significant decrease from $0.32 \pm 0.17$ to $0.27 \pm 0.17 \mathrm{U} / \mathrm{kg}$ ( $p=0.02$ ) (Fig. $2 \mathrm{~b})$. In addition, TBD/TDD decreased significantly from $44.8 \pm 12.3$ to $40.7 \pm 11.7 \%$ ( $p=0.02$ ) (Fig. $2 c)$. Significant decreases were observed with TDD, TBD, and TBD/TDD after about 24 weeks of use of insulin degledec (TBD: $p=0.03$, TDD: $p=0.02$, TBD/TDD: $p=0.03$ ) (Fig. 2a-c). 
A

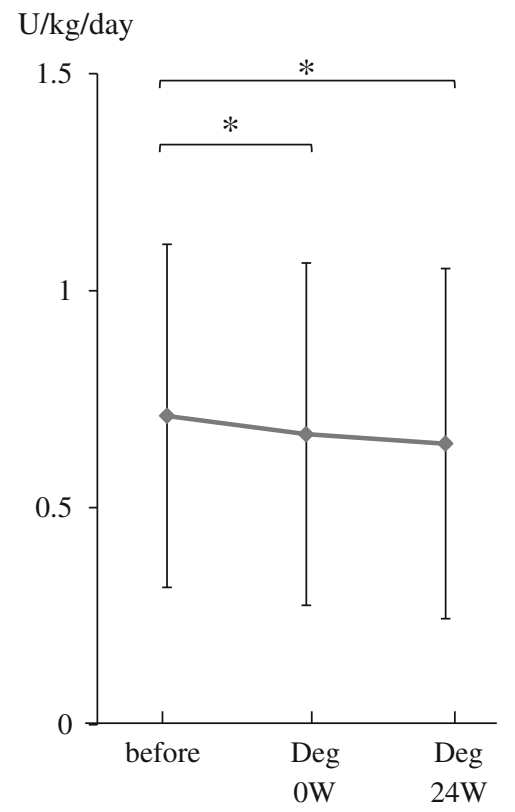

B

$\mathrm{U} / \mathrm{kg} / \mathrm{day}$

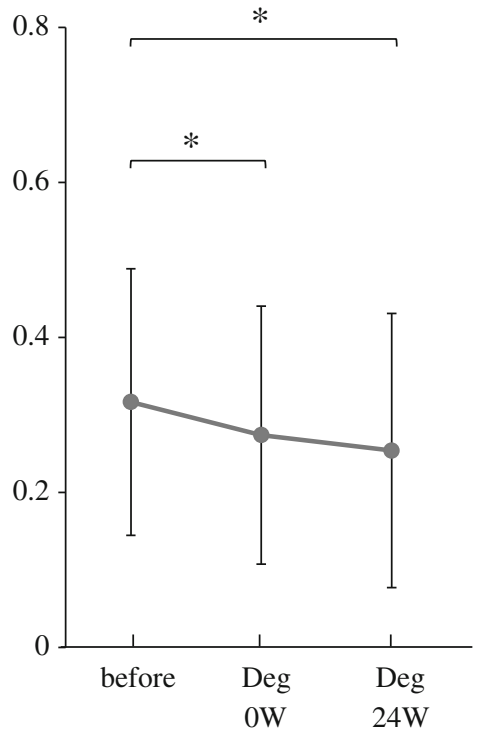

C

$\%$

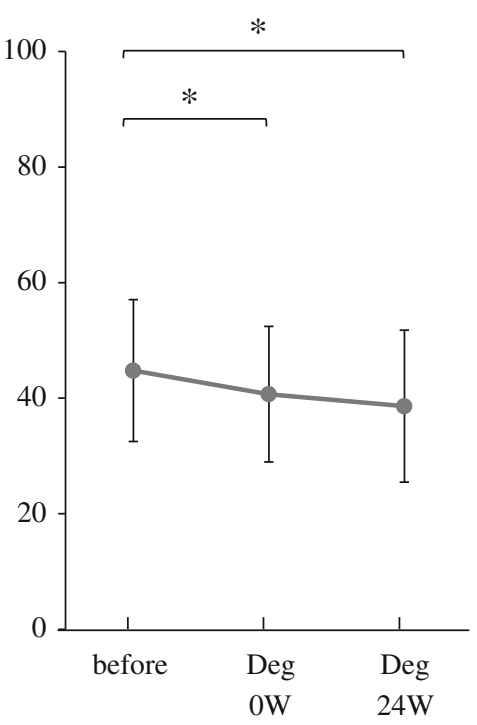

Fig. 2 Changes in (a) TDD, (b) TBD, and (c) TBD/TDD just before, and 0 and 20-30 weeks after switching to degludec. * $p<0.05$ versus baseline (glargine or detemir). Deg degludec, TBD total daily dose of basal insulin, TDD total daily dose of insulin, $W$ week

\subsection{Comparison of CGM Findings}

\subsubsection{Mean Daily Blood Glucose Level}

The mean blood glucose level showed no significant changes before and after switching from insulin glargine or detemir to insulin degludec (Fig. 3a).

No significant changes were also observed with the standard deviation (Fig. 3b) and mean amplitude of glycemic excursion (MAGE) (Fig. 3c) throughout the study period.

\subsubsection{Nocturnal Hypoglycemia}

Nocturnal hypoglycemia is defined as a blood glucose level of less than $70 \mathrm{mg} / \mathrm{dL}$ between 0000 and 0600 hours based on CGM data. Two patients developed nocturnal hypoglycemia before switching to insulin degludec, and two patients had nocturnal hypoglycemia at 24 weeks after switching to insulin degludec.

\subsubsection{Night-Time Blood Glucose Fluctuations}

When the night-time period was defined as between 0000 and 0600 hours, the area under the blood glucose concentration-time curve (AUC) from 0000 to 0600 hours was $782.7 \pm 277.2 \mathrm{mg} \cdot \mathrm{h} / \mathrm{dL}$ before switching to insulin degludec and $890.3 \pm 371.9 \mathrm{mg} \cdot \mathrm{h} / \mathrm{dL}$ at 3 days after switching, showing no significant change (Fig. 3d). No significant changes in the AUC from 0000 to 0600 hours were also observed after 24 weeks of use of insulin degludec $(859.3 \pm 399.8 \mathrm{mg} \cdot \mathrm{h} / \mathrm{dL})$ (Fig. 3d).

\subsection{Glycated Hemoglobin}

$\mathrm{HbA}_{1 \mathrm{c}}$ showed no significant changes in the 24 weeks after changing the type of insulin (from $7.3 \pm 0.9$ to $7.5 \pm 1.0 \%$ ).

\section{Discussion}

Previous studies have shown that insulin degludec and insulin glargine or detemir achieve similar glycemic control, but the frequency of nocturnal hypoglycemia was lower in patients treated with insulin degludec [8-13]. Heise et al. [14] showed that degludec had a significantly more predictable glucose-lowering effect on day-to-day variability than glargine. However, to date, no previous studies have assessed the medium-term effects of insulin degludec on blood glucose fluctuations and nocturnal hypoglycemia in patients with T1DM.

In this study, CGM did not reveal any changes of the frequency of nocturnal hypoglycemia at 24 weeks after switching to insulin degludec. We also found no significant changes in blood glucose fluctuation 3 days and 24 weeks after switching to insulin degludec at a lower dose than that of insulin glargine or detemir. These results suggest that 
A

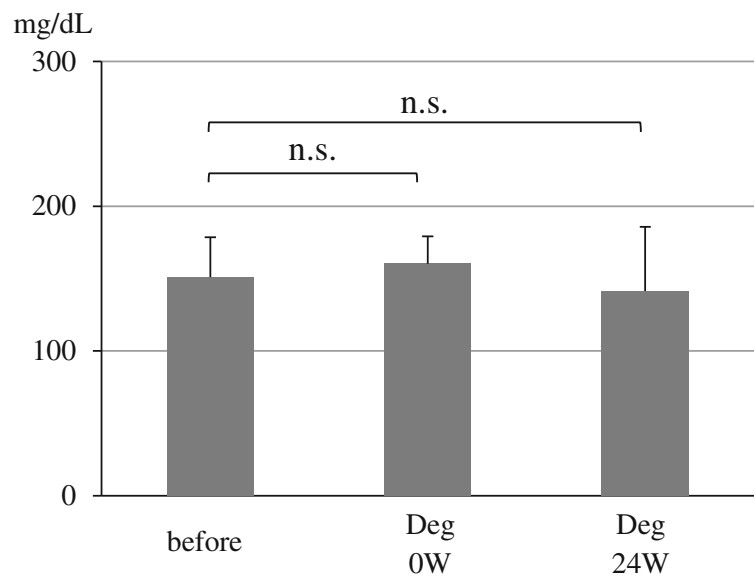

C

$$
\mathrm{mg} / \mathrm{dL}
$$

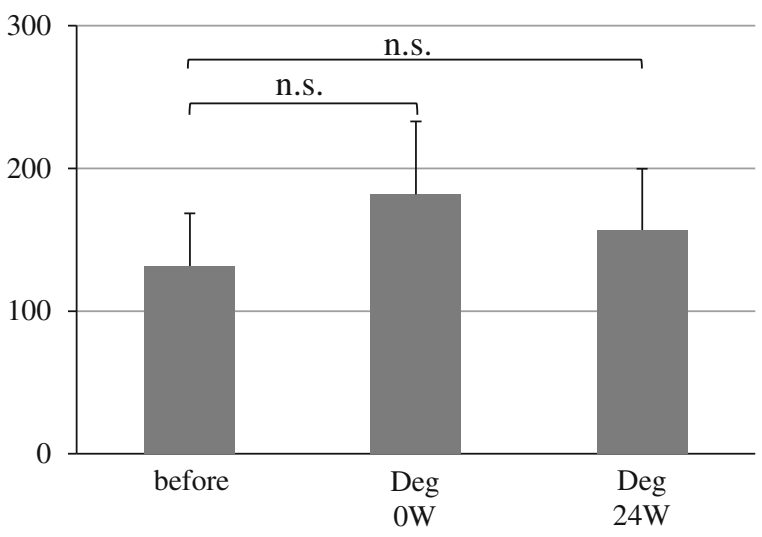

Fig. 3 Changes in (a) mean glucose, (b) standard deviation, (c) MAGE, and (d) AUC 0000-0600 hours versus baseline (glargine or detemir). AUC area under the blood glucose concentration-time

insulin degludec has a stronger hypoglycemic effect than glargine or detemir and may be used at a lower dose than other basal insulins in the treatment of patients, with lower fasting glucose levels and easily manageable hypoglycemia. Another study also reported similar results [15].

When once-daily injection of insulin glargine or detemir is used as basal insulin in patients with T1DM, large diurnal variations of blood glucose frequently develop due to the dawn phenomenon or Somogyi effect [16]. It has been reported that glycemic control in these patients can be improved by splitting the basal insulin dose into two portions to be given separately $[2,3]$. In the present study, all patients received twice-daily injection of insulin glargine or detemir prior to switching to degludec. Our results showed that once-daily injection of insulin degludec can maintain the glycemic control obtained by twice-daily administration of long-acting insulin.
B

$\mathrm{mg} / \mathrm{dL}$

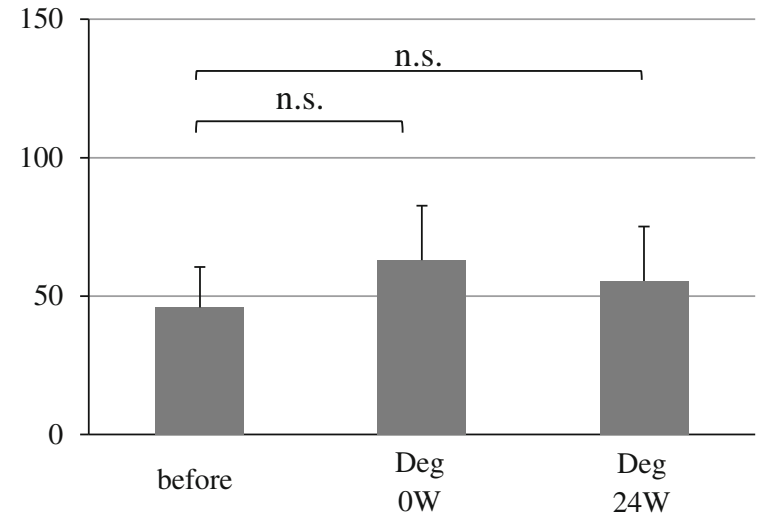

D

$\mathrm{mg} \cdot \mathrm{h} / \mathrm{dL}$

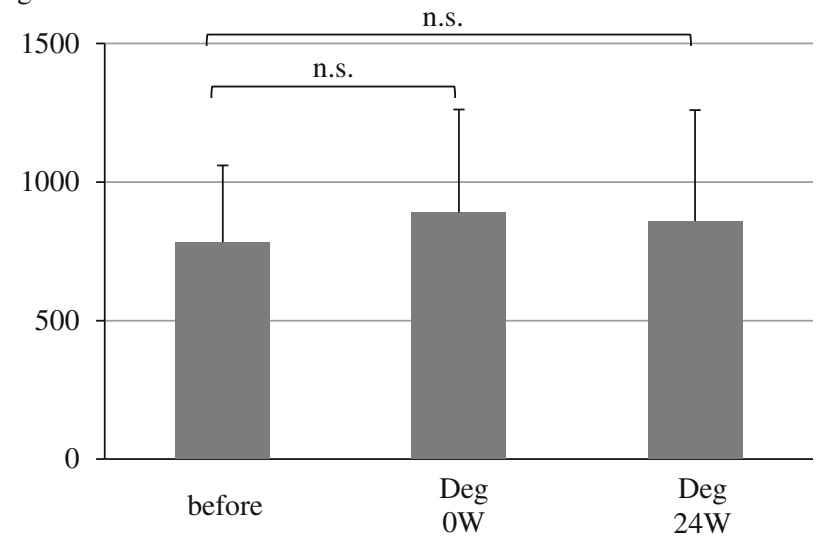

curve, Deg degludec, MAGE mean amplitude of glycemic excursion, n.s. not significant, $W$ week

The present study was open-label in design and was a non-crossover trial. Further work using a larger sample size and double-blind crossover comparison is desired.

\section{Conclusion}

In patients with T1DM, stable supplementation of basal insulin is essential to achieve good glycemic control. This study shows that it is possible to achieve similar glycemic control in the medium term with once-daily injection and lower doses of insulin degludec.

Acknowledgments Dr. R. Nakae is the guarantor for this article, and takes responsibility for the integrity of the work as a whole. No funding or sponsorship was received for this study or publication of this article. 
Conflict of interest R. Nakae, Y. Kusunoki, T. Katsuno, M. Tokuda, T. Akagami, K. Murai, T. Hamaguchi, J. Miyagawa, and M. Namba declare no conflict of interest.

Open Access This article is distributed under the terms of the Creative Commons Attribution Noncommercial License which permits any noncommercial use, distribution, and reproduction in any medium, provided the original author(s) and the source are credited.

\section{References}

1. Cheng AY, Zinman B. Principle of the insulin treatment. In: Kahn CR, Weir G, editors. Joslin's diabetes mellitus [in Japanese]. 14th ed. Tokyo: Medical Science International; 2007. p. 737-49.

2. Katsuno T, Hamaguchi $T$, Nagai E, et al. Influence of insulin glargine on basal insulin supplementation in Japanese type 1 diabetic patients treated with basal-bolus injection therapy [in Japanese]. J Japan Diabetes Soc. 2008;51:983-90.

3. Ashwell SG, Gebbie J, Home PD. Twice-daily compared with once-daily insulin glargine in people with type 1 diabetes using meal-time insulin aspart. Diabetes Med. 2006;23:879-86.

4. Jonassen I, Havelund S, Hoeg-Jensen T, Steensgaard DB, Wahlund PO, Ribel U. Design of the novel protraction mechanism of insulin degludec, an ultra-long-acting basal insulin. Pharm Res. 2012;29(8):2104-14.

5. Novo Nordisk Pharm Ltd [internal company data]. http://www. novonordisk.co.jp. Accessed 15 Nov 2013.

6. Kusunoki Y, Katsuno T, Miyakoshi K, et al. Effects of switching from insulin glargine or detemir to insulin degludec in patients with type 1 diabetes mellitus. Diabetes Ther. 2013;4(2):461-72.

7. Ogawa S, Nako K, Okamura M, et al. Compared with insulin glargine, insulin degludec narrows the day-to-day variability in the glucose-lowering effect rather than lowering blood glucose levels. J Diabetes Mellitus. 2013;3(4):244-51.

8. Heller S, Buse J, Fisher M, et al. Insulin degludec, an ultralongacting basal insulin, versus insulin glargine in basal-bolus treatment with mealtime insulin aspart in type 1 diabetes (BEGIN Basal-Bolus Type 1): a phase 3, randomised, open-label, treat-totarget non-inferiority trial. Lancet. 2012;379:1489-97.

9. Zinman B, Philis-Tsimikas A, Cariou B, et al. Insulin degludec versus insulin glargine in insulin-naive patients with type 2 diabetes: a 1-year, randomized, treat-to-target trial (BEGIN Once Long). Diabetes Care. 2012;35:2464-71.

10. Iwamoto $Y$, Clauson P, Nishida T, Kaku K. Insulin degludec in Japanese patients with type 1 diabetes mellitus: a randomized controlled trial. J Diabetes Investig. 2013;4:62-8.

11. Hirsch IB, Bode B, Courreges JP, et al. Insulin degludec/insulin aspart administered once daily at any meal, with insulin aspart at other meals versus a standard basal-bolus regimen in patients with type 1 diabetes: a 26-week, phase 3, randomized, open-label, treat-to-target trial. Diabetes Care. 2012;35:2174-81.

12. Bode BW, Buse JB, Fisher M, et al. Insulin degludec improves glycaemic control with lower nocturnal hypoglycaemia risk than insulin glargine in basal-bolus treatment with mealtime insulin aspart in Type 1 diabetes (BEGIN $\left({ }^{\circledR}\right)$ Basal-Bolus Type 1): 2-year results of a randomized clinical trial. Diabet Med. 2013;30:1293-7.

13. Mathieu C, Hollander P, Miranda-Palma B, et al. Efficacy and safety of insulin degludec in a flexible dosing regimen vs insulin glargine in patients with type 1 diabetes (BEGIN: Flex T1): a 26-week randomized, treat-to-target trial with a 26-week extension. J Clin Endocrinol Metab. 2013;98:1154-62.

14. Heise T, Tack CJ, Cuddihy R, et al. A new-generation ultra-longacting basal insulin with a bolus boost compared with insulin glargine in insulin-naive people with type 2 diabetes: a randomized, controlled trial. Diabetes Care. 2011;34:669-74.

15. Yamada K, Nakayama $\mathrm{H}$, Sato $\mathrm{S}$, et al. A randomized crossover study of the efficacy and safety of switching from insulin glargine to insulin degludec among patients with type 1 diabetes. Diabetol Int. 2014;5:74-7.

16. Bolli GB, Perriello G, Fanelli CG, De Feo P. Nocturnal blood glucose control in type I diabetes mellitus. Diabetes Care. 1993;16(Suppl 3):71-89. 